\begin{tabular}{|c|c|}
\hline APK I 79972 , ENGINEERING DATA TRANSMITTAL & 1. EDT No 614840 \\
\hline
\end{tabular}

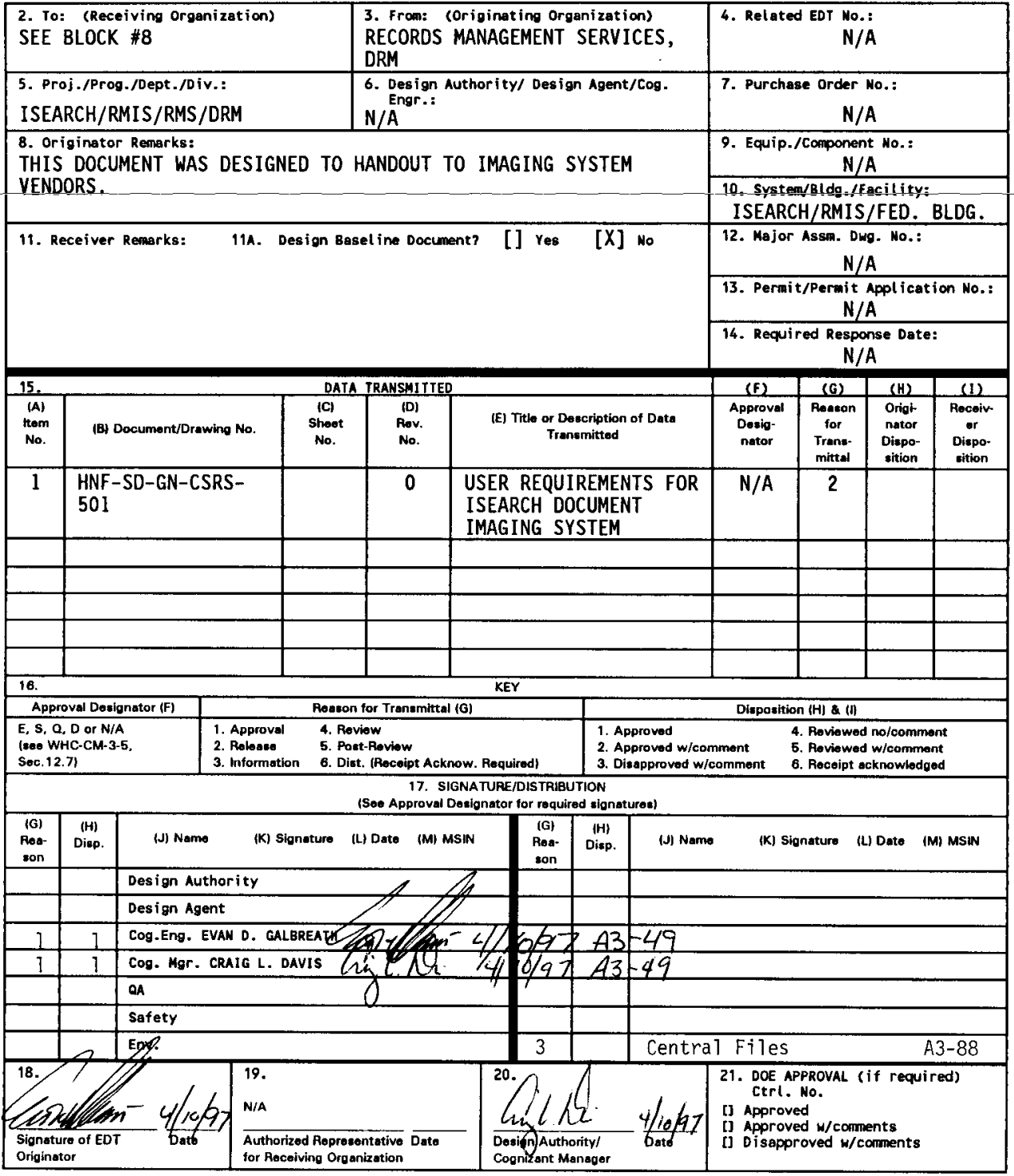

BD-7400- $172-2(05 / 96)$ GEF097 


\section{USER REQUIREMENTS FOR ISEARCH DOCUMENT IMAGING SYSTEM}

EVAN D. GALBREATH

Lockheed Martin Services, Inc., Richland, WA 99352

U.S. Department of Energy Contract DE-AC06-96RL13200

EDT/ECN: EDT-614840 UC: UC-505

Org Code: 07E00 Charge Code: MD650

B\&R Code: YNO10000 Total Pages: 5

Key Words: Computer Imaging Software

Abstract: This requirements document lists items that are needed for exploring replacement software for the existing imaging system for the RMIS/ISEARCH system.

Trademarks:

MS DOS is a product of Microsoft Inc.

MS Excel is a product of Microsoft Inc.

MS Word is a product of Microsoft Inc.

SQL is a product of Microsoft Inc.

Viewstar is a product of Mosaix.

Windows 95 is a product of Microsoft Inc.

TRADEMARK DISCLAIMER. Reference herein to any specific comercial product, process, or service by trade name, trademark, manufacturer, or otherwise, does not necessarily constitute or imply its endorsement, recommendation, or favoring by the United States Goverment or any agency thereof or its contractors or subcontractors.

Printed in the United States of America. To obtain copies of this document, contact: Document Control Services, P.O. Box 950, Mailstop H6-08, Richland WA 99352, Phone (509) 372-2420;

Fax (509) 376-4989.
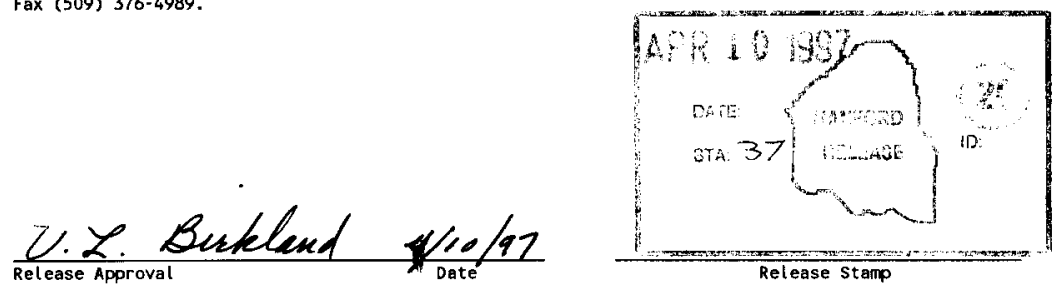

Approved for Public Release 
HNF-SD-GN-CSRS-501, Rev.0

\section{USER REQUIREMENTS FOR ISEARCH DOCUMENT IMAGING SYSTEM}

The Information Services Electronic ARCHiving (ISEARCH) system was designed and implemented in 1990 to make millions of pages of site information available to the site workers using the 486-based computer in their offices. This was a significant savings in cost and time to the site. Before ISEARCH, the general user had to drive to the central records storage facility from the jobsite, a distance of up to 30 miles one way. Searching for the information, getting it reproduced, and returning to the jobsite often took several hours. Frequently another customer would need the same information a week or so later, and have to go through the steps. With ISEARCH, users have immediate access to, and use of, the information right at their desktops.

Another problem that faced the site was that there were several different databases and "pockets" of information that were difficult to find and use. ISEARCH brought much of the information into a single system that is quick and easy to use.

The Hanford site in south central Washington state is 570 square miles in size. It is run by Fluor Daniel Hanford and other contractors for the Department Of Energy. Their primary mission is to clean up 40 years of plutonium production waste. These past 40 years have produced hundreds of millions of pages of information. For the most part this information sat in central facilities and repositories with very few search tools for seekers of information to use to find the desired information. The ISEARCH system was implemented to remedy the situation.

By no means is the ISEARCH system expected to capture all the site's huge volumes of information; however, to date the system does hold over 8 million images. We are adding approximately 10,000 new images per day to the system. It is capturing a wide variety of information such as Company Correspondence (which is scanned, indexed, and retrievable within 4 hours of when it's received), E-size (36"x44") Engineering Drawings, Supporting Documents, MSDS's, etc.

We have one central document processing area and approximately 12 other satellite processing areas that cover the Hanford site. There are about 70 "information processors" that input information on a daily basis into the system and over 1,000 users that have retrieval capability. We plan to have about 1,600 users with retrieval capability by the end of the fiscal year (September $30,1997)$. The site has approximately 9,000 employees.

Our system uses Viewstar software version 3.1.1 as our processing (scanning, indexing, and archiving) tool. We use a product produced by the Diamond Head software company, which we call Records Management Information System (RMIS) and RMIS View/Print (RMIS V/P), that has been redesigned somewhat to fit our own needs. The RMIS is the database that users access to perform searches for information. To assist the users, the "information processors" input into the RMIS database system search/index items such as document number, title, keywords, etc. Searches can be conducted on all 32 fields of indexed information. There is no record type that requires all 32 fields to be populated during indexing, but 32 fields are available to handle any 
HNF-SD-GN-CSRS-501, Rev. 0

record type that comes through to be processed.

The RMIS V/P is the viewing tool that the user uses to view the desired document once it has been found through searches. The images can be e-mailed, faxed, and/or printed to get the information to other users. We have one group that FTPs documents from Richland, Washington to Oak Ridge, Tennessee. Since March 1997, we have accepted the site Operating Procedures in native file format (in this case, WP 5.1) and are ready to accept other file formats such as MS Word, Excel, etc. These files can be distributed faster and cheaper to the customers who need them.

The purpose of this document is to provide our system information to a large audience such as the AIIM show in hopes that there may be one or more vendors that are interested and have the tools and resources available to help us cut costs and not lose our systems quality along the way.

We are really no different from any company in today's market that needs to take a hard look at how dollars are spent and return on investment. Our company has been under the Department of Energy (DOE) umbrella for several years. On October 1, 1996 a new set of contractors took over Hanford cleanup, and committed to helping transition the region's economy from reliance on government funding. In addition to providing our services to the DOE and Hanford employees, we are pursuing commercial independence over the next few years.

The biggest hurdle we face is to cut costs on software license and maintenance agreements to be competitive in the commercial marketplace. We would like to talk with vendors who would be interested in helping us convert, with minimal downtime, our 8 million+ images from the Mosaix (Viewstar) product to an imaging product that would cut our yearly costs on licensing and maintenance agreements.

I don't even know if this has been attempted in the past or not. I have to believe that someone has run into the same hurdles we have. Our current product is just too expensive for the benefits that we receive from it. The following information is a breakdown of what we feel are necessary features in order to maintain and hopefully improve our current product using another product. It is followed by a "wish list" that real users of the system have requested that aren't available with the Mosaix product:

\section{Requirements}

Overall:

- Operating system must be WFW 3.11/MS-DOS 6.22 or Windows 95 .

- Compatible with LAN technology. 


\section{HNF-SD-GN-CSRS-501, Rev.0}

\section{Document Processing And General User Features:}

- Able to support 9,000+ users. (This includes scanning, indexing, and retrievals.)

- Able to support single and/or multiple document processors performing multiple functions such as scanning, indexing, retrieving from the same workstations.

- $\quad$ Able to reject, repair, and re-index skewed and missing pages.

- $\quad$ Able to interface with existing RMIS \& RMIS V/P database and document viewing programs.

- Able to generate and print SQL-based Box Reports that show basic box information and reports.

- Generate a unique identifier (Accession \#) for each document processed through the system.

- Barcode technology (batch \#, document separators, etc.) used to prep/scan boxes.

Administrative Tasks:

- System Administrator(s) would need wide range of tools such as Workflow Admin., Security, batch creation capabilities, etc., in order to perform daily administrative duties.

- Automated nightly archiving capabilities. Note: We currently have a number of documents archived about every 15 minutes for quick electronic distribution.

- Able to support Sony 50 Platter Auto-Changer WORM Drive Jukeboxes with 6.55GB Optical platters.

- Ability to backup critical system files with high speed tape devices on a nightly basis.

General Programming And Software Maintenance Support:

- $\quad$ Imaging product must interface with Visual Basic and Image Basic programs (RMIS \& RMIS V/P programs) along with SQL Server program.

- Responsive and comprehensive technical support by phone or if necessary, on-site support in which travel costs are covered under the basic maintenance agreement.

- Minimal rework on Scripting for our programmers to tailor to our site needs.

- Take advantage of and interface with Intranet and Internet technologies.

- $\quad$ Ability to use OCR technologies.

- $\quad$ Profit sharing for any new technologies which we help develop.

General User "Wish List": (Not Required)

- Ability to repair documents after archiving in which mistakes weren't caught so document doesn't have to be deleted and rescanned.

- Imaging product able to assist processors of the information to change paper sizes, etc., "On the fly".

- Possibly have product interface with automated indexing technologies, so a target sheet could be scanned and have it populate several key indexing fields. (Or perhaps the 
HNF-SD-GN-CSRS-501, Rev.0

product could even provide voice-activated indexing capabilities.)

If anything here sounds like something your company might have an interest in further discussing, please contact:

Evan D. Galbreath, ISEARCH System Administrator

Lockheed Martin Services, Inc.

P.O. Box 950, Mailstop A3-49

Richland, WA 99352

e-mail: evan_d_galbreath@rl.gov

Phone: (509) 373-1650

Fax: (509) 376-4931

Craig L. Davis, Manager

Lockheed Martin Services, Inc.

P.O. Box 950, Mailstop A3-49

Richland, WA 99352

e-mail: craig_1_davis@rl.gov

Phone: (509) 376-0238

Fax: (509) 372-0788 